\title{
New evidence for the links between the local water cycle and the underground wet sand layer of a mega-dune in the Badain J aran Desert, China
}

\author{
Jun WEN ${ }^{1 *}$, ZhongBo SU ${ }^{2}$, TangTang ZHANG ${ }^{1}$, Hui TIAN ${ }^{1}$, YiJian ZENG ${ }^{2}$, Rong LIU ${ }^{1}$, Yue KANG ${ }^{1}$, \\ Rogier van der VELDE ${ }^{2}$ \\ ${ }^{1}$ Key Laboratory of Land Surface Process and Climate Change in Cold and Arid Regions, Cold and Arid Regions \\ Environmental and Engineering Research Institute, Chinese Academy of Sciences, Lanzhou 730000, China; \\ ${ }^{2}$ Faculty of Geo-Information Science and Earth Observation (ITC), University of Twente, 7500 AA, Enschede, the Netherlands
}

\begin{abstract}
Scientists and the local government have great concerns about the climate change and water resources in the Badain Jaran Desert of western China. A field study for the local water cycle of a lake-desert system was conducted near the Noertu Lake in the Badain Jaran Desert from 21 June to 26 August 2008. An underground wet sand layer was observed at a depth of $20-50 \mathrm{~cm}$ through analysis of datasets collected during the field experiment. Measurements unveiled that the near surface air humidity increased in the nighttime. The sensible and latent heat fluxes were equivalent at a site about $50 \mathrm{~m}$ away from the Noertu Lake during the daytime, with mean values of 134.4 and $105.9 \mathrm{~W} / \mathrm{m}^{2}$ respectively. The sensible heat flux was dominant at a site about $500 \mathrm{~m}$ away from the Noertu Lake, with a mean of $187.7 \mathrm{~W} / \mathrm{m}^{2}$, and a mean latent heat flux of only $26.7 \mathrm{~W} / \mathrm{m}^{2}$. There were no apparent differences for the land surface energy budget at the two sites during the night time. The latent heat flux was always negative with a mean value of $-12.7 \mathrm{~W} / \mathrm{m}^{2}$, and the sensible heat flux was either positive or negative with a mean value of $5.10 \mathrm{~W} / \mathrm{m}^{2}$. A portion of the local precipitation was evaporated into the air and the top-layer of sand dried quickly after every rainfall event, while another portion seeped deep and was trapped by the underground wet sand layer, and supplied water for surface psammophyte growth. With an increase of air humidity and the occurrence of negative latent heat flux or water vapor condensation around the Noertu Lake during the nighttime, we postulated that the vapor was transported and condensed at the lakeward sand surface, and provided supplemental underground sand pore water. There were links between the local water cycle, underground wet sand layer, psammophyte growth and landscape evolution of the mega-dunes surrounding the lakes in the Badain Jaran Desert of western China.
\end{abstract}

Keywords: mega-dune; water cycle; observation; wet sand layer; Badain Jaran Desert

Citation: Jun WEN, ZhongBo SU, TangTang ZHANG, Hui TIAN, YiJian ZENG, Rong LIU, Yue KANG, Rogier van der VELDE. 2014. New evidence for the links between the local water cycle and the underground wet sand layer of a mega-dune in the Badain Jaran Desert, China. Journal of Arid Land, 6(4): 371-377. doi: 10.1007/s40333-014-0062-0

The causes why there are numerous lakes in the Badain Jaran Desert have been widely explored in the past several decades (Zhao and Chen, 2006; Dong et al., 2013), while the local water cycle and land surface process of this lake-desert system have seldom been investigated. In the last half century, many researchers have explored the evolution of mega-dunes from multiple approaches including desert landscapes, under- ground hydrology and geological tectonics, and raised several hypotheses, such as wind erosion (Yan et al., 2001) and underground water maintenance (Chen et al., 2004). Researchers have questioned the theory that underground rivers are the water source for the lakes surrounded by mega-dunes (Chen et al., 2004). A recent research indicated that there were some new lakes and area increases in some lakes, although the

*Corresponding author: Jun WEN (E-mail: jwen@lzb.ac.cn)

Received 2013-06-29; revised 2013-09-29; accepted 2013-10-25

(C) Xinjiang Institute of Ecology and Geography, Chinese Academy of Sciences, Science Press and Springer-Verlag Berlin Heidelberg 2014 
number and the area of lakes were reduced during 1973-2013 (Zhang et al., 2013). The moisture in mega-dune areas may be one of the sources of lakes and groundwater (Zhao et al., 2011). However, psammophytes are sparsely distributed on the slopes of the mega-dunes that faced the lakes. These psammophytes are drought tolerant, requiring less nutrition and water supplies, and prefer sunshine and an open-air environment. It would be difficult to supply water for the growth of these psammophytes, under such circumstances of sparse precipitation combined with the high altitudes of the mega-dunes. This prompted us to ask the following question: where is the source of water found in the underground wet layers of the mega-dunes?

To answer this question, our investigation involved the study of the local water cycle in this special landscape. With this motivation, our research presented new evidence for the links between the local water cycle, landscape evolution and the underground wet layers of the mega-dunes.

\section{Study area}

The study area $\left(39^{\circ} 45^{\prime}-39^{\circ} 47^{\prime} \mathrm{N}, 102^{\circ} 26^{\prime}-102^{\circ} 29^{\prime} \mathrm{E}\right)$ is located in the Badain Jaran Desert of western China, in the interior of the Eurasian Continent and on the western fringe of the Mongolian Plateau (Fig. 1a). With an area of $4.92 \times 10^{4} \mathrm{~km}^{2}$, the Badain Jaran Desert is the second largest drifting desert in China (Aoki et al., 2005; Chen et al., 2006). Numerous mega-dunes are distributed in the southern and southeastern parts of the desert. These mega-dunes are remarkable and are the tallest on Earth, with relative heights ranging from 200 to 300 m (Dong et al., 2004; Gu et al., 2004). More than 70 lakes are interspersed among the mega-dunes, and about 20 of these lakes contain fresh water (Chen et al., 2005). This area is in a typical arid continental climatic zone, with cold, dry winters, large diurnal temperature ranges, hot summers with long periods of sunlight, year-round northwestward winds, and a mean annual precipitation of below $50 \mathrm{~mm}$, which is concentrated in June and July (Wang, 1990). The increasing rate of the annual mean temperature nearby this desert is higher than that of the average of China, and there is no evident trend of increasing precipitation in the past decades (Zhu and Chang, 2011). There is a deceasing trend of precipitation in the desert compared to regions of the same latitude outside the desert (Zhang et al., 2012). Light rain dominates the hinterland and rainfall events are likely to be short in duration, usually less than two hours (Wang et al. 2013). The near surface radiation balance is highly relevant to local precipitation (Wang et al., 2011; Ma et al., 2012). Soil heat flux shows greatest diurnal variations at the depth of $5 \mathrm{~cm}$ and little variation at $20 \mathrm{~cm}$ (Li et al., 2012a).
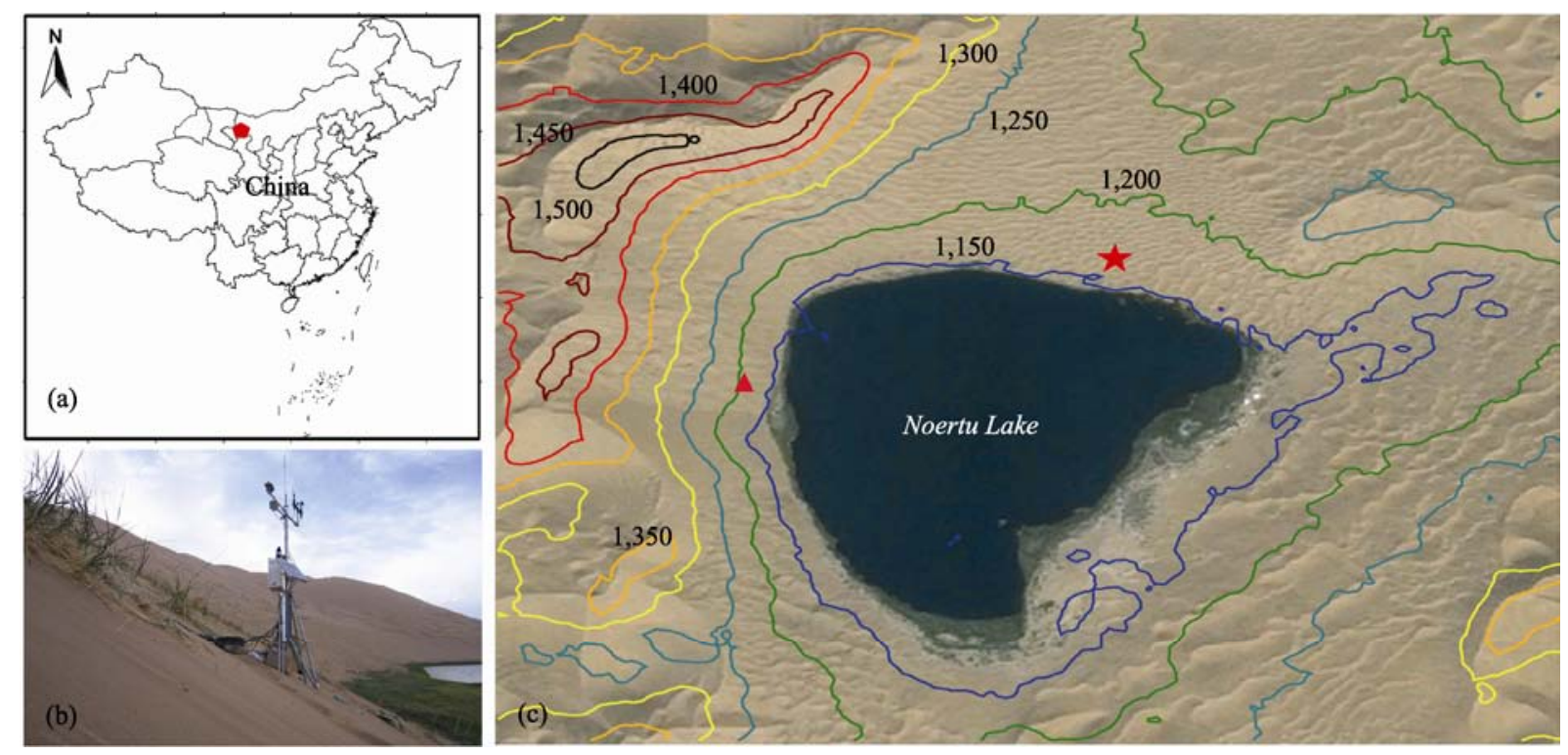

Fig. 1 The geographic location of the Badain Jaran Desert (a), the sparse psammophytes distributed along the slope of the mega-dune (b), and the landscape and DEM of the dune-lake system of the experiment conducted in the Badain Jaran Desert (c). $\star$ is the site of the automatic weather station, and $\boldsymbol{\Delta}$ is the eddy covariance turbulence flux system. 


\section{Experimental design}

To investigate the existing links between the local water cycle and the underground wet sand layers of the mega-dunes, we conducted a field experiment on the local water cycle around the Noertu Lake in the Badain Jaran Desert of western China (Fig. 1). Sand moisture, sand water potential, sand temperature and properties of the plants growing on the slope of a mega-dune by the lake were also measured. The Noertu Lake is located in the southeast of the Badain Jaran Desert, about $30 \mathrm{~km}$ away from the Yabulai mountain range in the southeastern fringe of the desert. The surface area of the Noertu Lake is approximately $2.6 \mathrm{~km}^{2}, 1.3 \mathrm{~km}$ in width (from east to west) and $1.6 \mathrm{~km}$ in length (from north to south), and has a maximal depth of approximately $16 \mathrm{~m}$ (Dong et al., 2003). On the west of the Noertu Lake resides a mega-dune with a relative height of approximately $300 \mathrm{~m}$. Psammophytes are sparsely distributed on the slope of the mega-dune that faces the lake, with heights of approximately $10 \mathrm{~cm}$ and roots that reach more than $100 \mathrm{~cm}$. On the eastern side of the lake is a sand-hill, and on the northern side there are lower drifting sand hills, reeds, bushes and psammophytes growing by the lakeside. The vertical variation in the distribution of sand grain sizes was very small. Sand grains with the diameters of $0.075-0.100 \mathrm{~mm}$ and larger than $0.100 \mathrm{~mm}$ take $9.4 \%$ and $89.4 \%$ of a unit volume, respectively. This sand texture facilitates vapor transport to the sand surface where it condenses (Agam et al., 2006), whereas the transport of moisture from the deeper sand layer to the surface and into the air for evaporation is much more difficult.

Our field experiment consisted of two periods. The first period was from 1 June to 22 June 2008. A site $50 \mathrm{~m}$ away from the lake was chosen, with the goal of measuring the contributions of both the surface of the lake and the surface of the sand to the local water cycle. The second period was from 22 June to 22 August 2008. A site $500 \mathrm{~m}$ from the lake was selected to validate the contribution of the sand surface to the local water cycle. To monitor the air temperature, wind velocity and vapor content of the lake-desert system, we installed an automatic weather station at the middle of the western lakeward slope of the mega-dune beside the lake. The observation period ranged from 18 June to 26 August 2008. The vertical profiles of sand moisture, temperature and properties of the psammophytes were also investigated and non-periodically measured or sampled.

To ensure the quality of the datasets collected during the field experiment, we tested or calibrated all instruments and sensors in a pilot experiment conducted prior to the start of the formal experiment, including the sand moisture sensors, which were calibrated by using the gravity sample method in our laboratory. All unacceptable values were rejected from datasets. The datasets were subjected to statistical analysis to ensure their reliability. All the datasets were analyzed by using Excel and Origin software.

\section{Results and discussion}

\subsection{The underground wet sand layer around the lake}

To investigate the vertical structure of sand temperature and moisture on the mega-dune slope, we averaged sand temperature and moisture profiles after three rainfall events (precipitations were $23.9 \mathrm{~mm}$ on 30 July 2008, $14.7 \mathrm{~mm}$ on 8 August 2008 and 11.4 mm on 15 August 2008, respectively). The temporal variations of the average sand temperature and moisture were plotted in Fig. 2. We observed that a clear diurnal cycle for the top-layer sand temperature was displayed, while the diurnal temperature variations of the lower-layer sand were unclear; the diurnal cycle signal reached a maximum depth of $60 \mathrm{~cm}$, and during the periods of rainfall the temperature dropped. Figure 2 also indicates that the rainfall was the cause of the sand moisture variation, which suggests that an underground wet-sand layer did exist at the $20-60 \mathrm{~cm}$ depth. The average volumetric sand moisture ranged from $15 \%$ to $20 \%$ at this depth range, and the sand moisture beneath or beyond this layer decreased. At the extremely dry surface of the mega-dune, the magnitudes of diurnal surface temperature cycles were very large, while signals for the deep-layer sand diurnal temperature cycles were not clear because of sand moisture and lower energy transmittance of the dry surface of the mega-dune. With extremely dry conditions at the surface of the mega-dune, the rate of evaporation was very high. However, the underground sand moisture did not readily evaporate and became trapped in the underground wet sand layer. During the 
period of the field experiment, we analyzed the structure of plant roots growing on the lakeward slope of the mega-dune on the western side of the lake. Our result indicated that the distribution depth of the dry sand layer in the mega-dune area is larger than that in a precipitation area, and the location of the wet sand layer is lower than that of an area with more precipitation (Zhao et al., 2011). This result is based on the analysis of deep soil moisture datasets. Furthermore, it was found that many roots were horizontally distributed within depths of 30-60 cm, which indirectly validates the fact that this layer had high moisture content, which is consistent with past investigations in semi-arid zones (Breshears and Barnes, 1999). Because there was little water vapor condensation and few psammophytes growing, no evident showed that there was an underground wet sand layer existed on the mega-dune backside of the lakeward slope.

\subsection{The meteorological condition and local water cycle near the lake}

The mean diurnal cycle of the local wind direction,

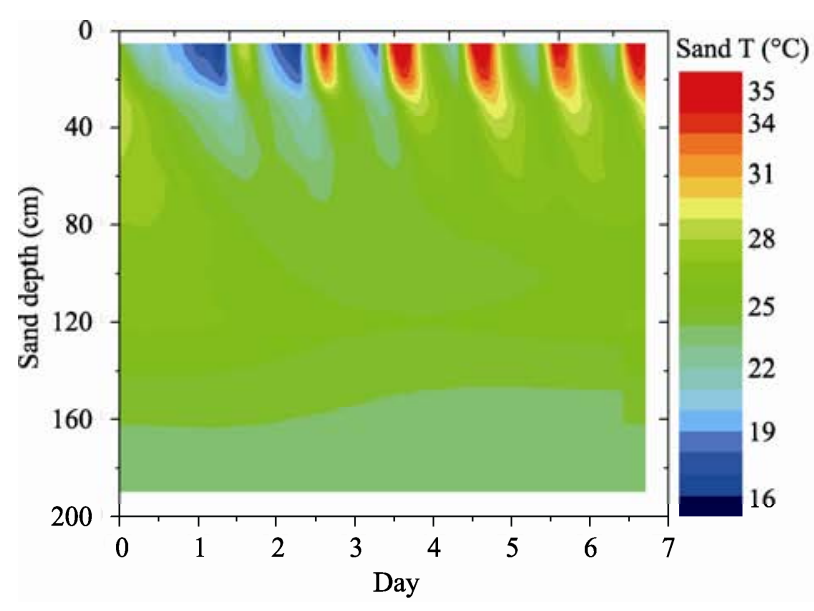

wind velocity, air temperature and air humidity were obtained by processing data collected from the automatic weather station. As displayed in Fig. 3a, a change in wind direction was evident at low velocities. The wind blew toward the lake during the daytime (mean direction $120.2^{\circ}$ ) and away from the lake during the nighttime (mean direction $197.4^{\circ}$ ). The local wind velocity increased from 07:00 and reached a maximum of $2.6 \mathrm{~m} / \mathrm{s}$ at 13:00 with a daily average of $0.9 \mathrm{~m} / \mathrm{s}$. The diurnal air temperature cycle exhibited a typical sinusoidal shape, while the absolute humidity of the air increased from 19:00 and reached a maximum of $8.9 \mathrm{~g} / \mathrm{m}^{3}$ by the next day at 08:00 (Fig. 3b). Due to the low sand surface temperature during the night time hours, air vapor contents were higher. The vapor condensed on the lakeward slope of the mega-dune and was transported to the lower-layer of the mega-dune surface where it maintained the underground wet sand layer. However, these phenomena did not occur on the mega-dune backside of the lakeward slope. This implied that there were direct links between the local water cycle, underground wet sand

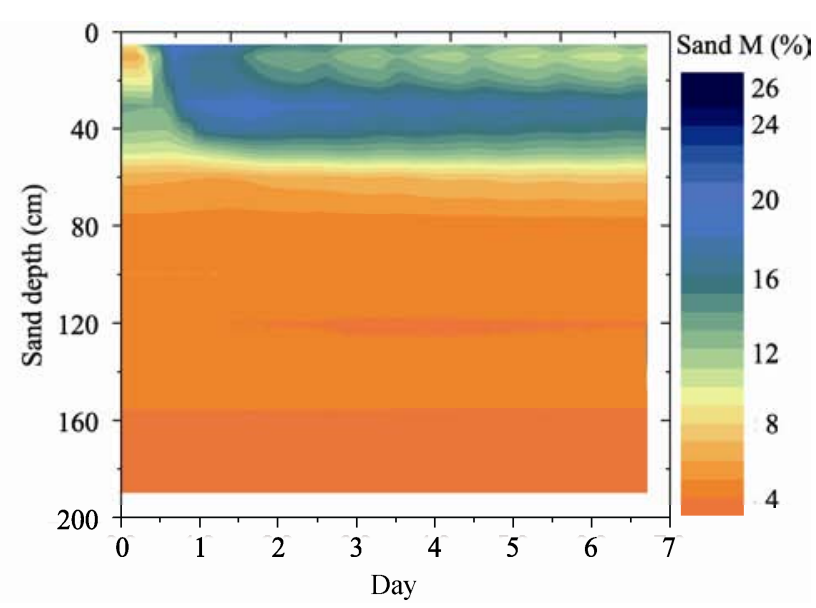

Fig. 2 The mean temporal variation of sand temperature (a) and sand moisture (b) profile of the mega-dune
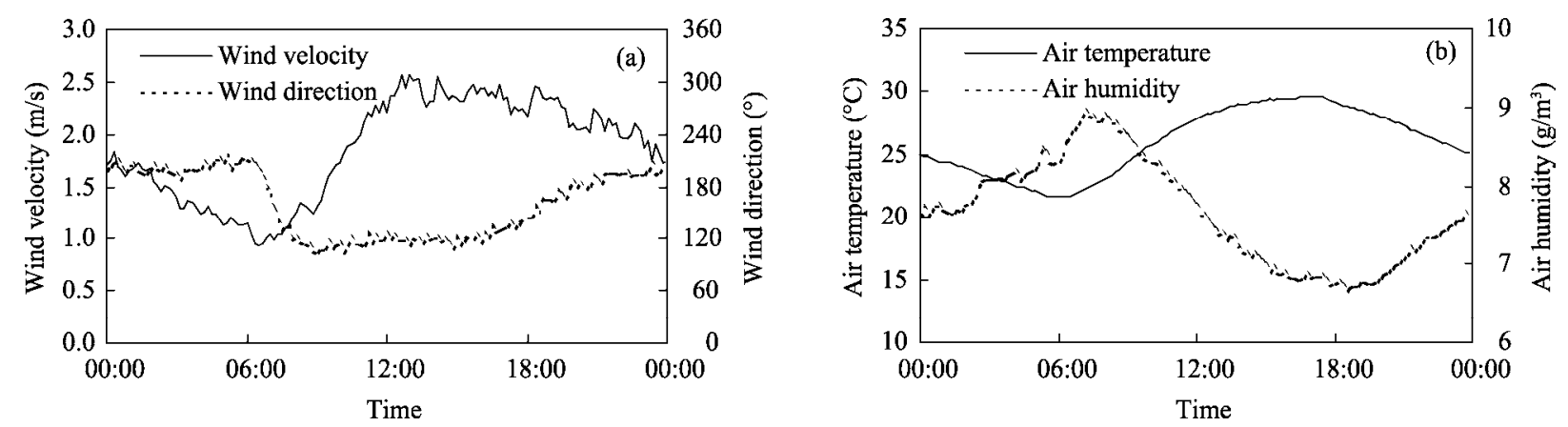

Fig. 3 The mean diurnal cycles of the wind velocity and direction (a) and air temperature and humidity (b) on the slope of the mega-dune around the lake 
layer and the psammophytes growing on the mega-dune. Considering the height of the mega-dune, the underground water table would be very deep relative to the surface of the mega-dune. The deep sand capillary movement was extremely weak, so the water that maintains the wet sand layer and the psammophytes should be contributed by local precipitation and condensed water. These results are consistent with the micrometeorology observations on the breeze over Lake Ngoring and Erhai lakeside regions ( $\mathrm{Li}$ et al., 2012b; Xu et al., 2012) and the numerical simulation of circulations over oasis regions (Chen et al., 2004; Chen et al., 2006).

\subsection{Impacts of local precipitation on the desert- atmospheric interaction}

To qualitatively understand the links between the sand surface-atmosphere water exchange and the underground wet sand layer, we analyzed datasets measured by the eddy covariance turbulent flux measurement system and obtained the diurnal cycle and characteristics of the land surface energy budget. During the first period, in the daytime (10:00-16:00), sensible and latent heat fluxes were equivalent in the land-atmosphere energy exchange at the site $50 \mathrm{~m}$ away from the lake, with mean values of 134.4 and $105.9 \mathrm{~W} / \mathrm{m}^{2}$, respectively. Both lake and sand surfaces in this case contributed to energy fluxes. During the second period, in the daytime (10:00-16:00), the sensible heat flux was dominant in the land-atmosphere energy exchange at the site $500 \mathrm{~m}$ away from the lake, with a mean sensible heat flux of $187.7 \mathrm{~W} / \mathrm{m}^{2}$ and a mean latent heat flux of only $26.7 \mathrm{~W} / \mathrm{m}^{2}$. There were no evident differences in the sensible and latent heat fluxes at the two sites during the nighttime hours (20:00-08:00), with a mean latent heat flux (always a negative value) of $-12.7 \mathrm{~W} / \mathrm{m}^{2}$ and a mean sensible heat flux (with either a positive or a negative value) of $4.1 \mathrm{~W} / \mathrm{m}^{2}$. Although there was an underground wet sand layer at the $20-60 \mathrm{~cm}$ depth, the potential for evaporation from this land surface was very low. Among all the collected samples that comprise the dataset, there were 1,013 negative latent heat flux samples taken, which were about $26.2 \%$ of the entire dataset and had a mean value of $-6.7 \mathrm{~W} / \mathrm{m}^{2}$; there were 1,546 negative sensible heat flux samples, which were about $39.7 \%$ of the entire dataset and had a mean value of $-6.5 \mathrm{~W} / \mathrm{m}^{2}$. This implies that the vapor was transported downward to the sand surface, and it is possible that condensation occurred at the sand surface during the nighttime (Wang et al., 1992).

Figure 4 presents the temporal variation of the sand surface latent heat, sensible heat and net radiation fluxes after every rainfall event. It indicates that the sand surface reflectivity gradually increased after every rainfall event because the sand surface was transitioned from wet to dry. While a portion of the precipitation directly seeped into the low sand layer at a depth of 20-60 cm, another portion of the precipitation was evaporated into the air. The sand surface became dry fast, and the rate of evaporation decreased very quickly, with a maximum daily latent heat flux that decreased from 184.3 to $41.2 \mathrm{~W} / \mathrm{m}^{2}$. As the sand surface became extremely dry, the sensible heat flux increased from 135.3 to $235.7 \mathrm{~W} / \mathrm{m}^{2}$. Past researches indicated that this caused the infiltration of precipitation to reach lower levels and become the import source of lake water in extremely dry conditions,

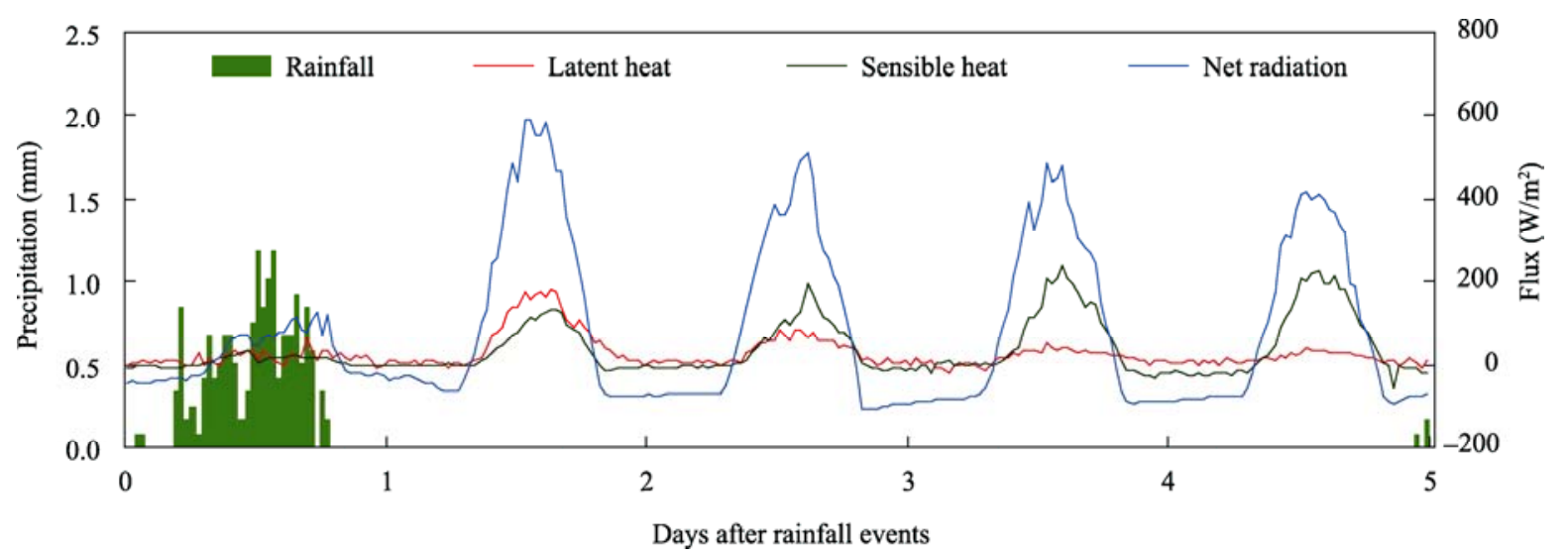

Fig. 4 The temporal variation of near-surface latent heat, sensible heat and net radiation fluxes after every rainfall event 
while the effect of evaporation was very small (Zhao et al., 1999). With a comprehensive analysis of data pertaining to the sand moisture profile, we can conclude that a portion of the precipitation was evaporated into the air at the top of the sand surface, and another portion seeped to the lower sand layer and was trapped by the wet sand layer.

We proposed that the seeped precipitation had a direct contribution to the maintenance of the underground wet sand layer of the mega-dune. The special landscape, extremely dry surfaces and negative latent heat flux caused the vapor to be transported to the underlying sand surface. The sand surface was extremely dry and the capillary action for the vertical transport of water was broken at the top sand layer. It was not possible for the deeper moisture to be up-taken and evaporated into the air even if the daytime net radiation flux was very large. Additionally, the trapped water maintained the underground wet sand layer. The moisture in the sand acted as an adhesive between sand particles, causing resistance to wind erosion and particle movement, maintaining the landscape of the mega-dune. The moisture also supplied water that enabled the growth of psammophytes found on the lakeward slope of the mega-dune.

\section{Conclusions}

This paper explored the links between the local water cycle and the underground wet sand layer of a mega-dune in the Badain Jaran Desert of western China. The following conclusions were drawn. The local water cycle of the dune-lake system in the Badain Jaran Desert maintained the existence of the wet sand layer and supplied water for the growth of psammophytes on the lakeward slope of the mega-dune. Precipitation seepage was the main water source for the underground wet sand layer of the mega-dune in the Badain Jaran Desert, and the negative latent heat flux or water vapor condensation had a contribution to the existence of the underground wet sand layer. Our results revealed the links between the local water cycle, psammophyte growth and landscape evolution of the mega-dune.

\section{Acknowledgements}

This research was supported by the European FP7 Programme:
CORE-CLIMAX (313085), the National Natural Science Foundation of China (41175027), the Key Research Program of the Chinese Academy of Sciences (KZZD-EW-13) and Chinese Academy of Sciences Fellowship for Young International Scientists (2012Y1ZA0013).

\section{References}

Agam N, Berliner P R. 2006. Dew formation and water vapor adsorption in semi-arid environments-a review. Journal of Arid Environments, 65(4): 572-590.

Aoki T, Mikami M, Yamazaki A. 2005. Spectral albedo of desert surfaces measured in western and central China. Journal of the Meteorological Society of Japan, 83(A): 279-290.

Breshears D D, Barnes F J. 1999. Interrelationships between plant functional types and soil moisture heterogeneity for semiarid landscapes within the grassland/forest continuum: a unified conceptual model. Landscape Ecology, 14(5): 465-478.

Chen J S, Li L, Wang J Y, et al. 2004. Water resources: groundwater maintains dune landscape. Nature, 432(7016): 459-460.

Chen J S, Zhao X, Sheng X F. 2005. Geochemical information indicating the water recharge to lakes and immovable megadunes in the Badain Jaran Desert. Acta Geologica Sinica, 79(4): 540-546.

Chen J S, Zhao X, Sheng X F. 2006. Formation mechanisms of megadunes and lakes in the Badain Jaran Desert, Inner Mongolia. Chinese Science Bulletin, 51(24): 3026-3034.

Chen S Q, Wen L J, Zhang Y, et al. 2006. Numerical simulation of local circulation in jinta Jinta oasis in summer. Plateau Meteorology, 25(1): 66-73.

Chen Y C, Lu S H, Gao Y H. 2004. Numerical simulation of circulation and boundary layer characteristics in oasis on different scales. Plateau Meteorology, 23(2), 177-183.

Dong Z B, Wang T, Wang X M. 2004. Geomorphology of the megadunes in the Badain Jaran Desert. Geomorphology, 60(1-2): 191-203.

Dong Z B, Qian G Q, Lv P, et al. 2013. Investigation of the sand sea with the tallest dunes on Earth: China's Badain Jaran Sand Sea. Earth-Science Reviews, 120: 20-39.

Gu W Z, Chen J S, Wang J Y, et al. 2004. Challenge from the appearance of vadose water within the surface layer of megadunes, Badain Jaran dune desert, Inner Mongolia. Advances in Water Science, 15(6): 695-699.

Li J G, Ao Y H, Li Z G. 2012a. Comparative analysis of radiation and energy budget over Badain Jaran Desert on clear and cloudy days in summer. Progress in Geography, 31(11): 1443-1451.

Li Z G, Lu S H, Ao Y H, et al. 2012b. Analysis of micrometeorology and $\mathrm{CO}_{2}$ flux characteristics over lake Ngoring lakeside region in summer. Progress in Geography, 31(5): 602-608.

Ma D, Lu S H, Ao Y H, et al. 2012. Analyses on radiation balance and surface energy budget in the Badain Jaran Desert in summer. Plateau Meteorology, 31(3): 615-621.

Xu A L, Zhao X H, Fu Z J, et al. 2011. Comparison of meteorological elements over water and land surfaces in the Erhai lake basin. Transactions of Atmospheric Sciences, 34(2): 225-231.

Wang J, Mitsuta Y. 1992. Evaporation from the desert: some preliminary results of HEIFE. Boundary-Layer Meteorology, 59: 413-418. 
Wang N A, Ma N, Chen H B, et al. 2013. A preliminary study of precipitation characteristics in the hinterland of Badain Jaran Desert. Advances in Water Science, 24(2): 153-160.

Wang T. 1990. Formation and evolution of Badain Jaran Sandy Desert, China. Journal of Desert Research, 10(1): 29-40.

Wang X, Wen J, Liu R, et al. 2011. Analysis of rainfall influence on solar radiation near land surface in the Badain-Jaran Desert. Arid Meteorology, 29(4): 615-621.

Yan M C, Wang G Q, Li B S, et al. 2001. Formation and growth of high megadunes in Badain Jaran Desert. Acta Geographica Sinica, 56(1): 83-91.

Zhang K C, Yao Z Y, An Z S, et al. 2012. Wind-blown sand environment and precipitation over the Badain Jaran Desert and its adjacent regions. Journal of Desert Research, 32(6): 1507-1511.

Zhang Z Y, Wang N A, Wu Y, et al. 2013. Remote sensing on spatial changes of lake area in Badain Jaran Desert hinterland during 1973-2010. Scientia Limnologica Sinica, 25(4): 514-520.

Zhao J B, Sao T J, Hou Y L, et al. 2011. Moisture content of sand layer and its origin in a mega-dune area in the Badain Jaran Desert. Journal of Natural Resources, 26(4): 694-702.

Zhao X, Chen J S. 1999. Application of similarity priority ratio on resources of groundwater in Badain Jaran Desert and its surrounding areas. Scientia Limnologica Sinica, 18(4): 407-413.

Zhu S J, Chang Z F. 2011. Temperature and precipitation trends in Minqin Desert during the period of 1961-2007. Journal of Arid Land, 3(3): 214-219. 